\title{
Do parents and adolescents talk about reproductive health? Myanmar adolescents' perspective
}

\author{
Yin Thet Nu Oo ${ }^{1}$, Ko Ko Zaw ${ }^{2}$, Kyu Kyu Than ${ }^{3}$, The Mg Mg ${ }^{4}$, Kyi Kyi Mar ${ }^{5}$, San San Aye \\ ${ }^{1,4}$ Research Officer; ${ }^{2}$ Research Scientist; ${ }^{5,6}$ Research Assistant; Department of Medical Research (Lower Myanmar), \\ Yangon, Myanmar. ${ }^{3}$ Technical Coordinator, Burnet Institute Myanmar, Yangon, Myanmar.
}

\begin{abstract}
Adolescence is a transitional period and an important stage in an individual's life. Adolescents are at risk of adverse reproductive health outcomes such as unplanned or unwanted pregnancy, unsafe abortions, maternal health complications, and sexually transmitted diseases (STDs) including HIV/AIDS. Previous studies indicate that adolescents whose parents talk to them about sex tend to be less sexually active and more likely to use an effective means of contraception. The objective of the study was to find out the level and content of communication between adolescents and their parents. Ease of communication, future intentions to discuss with parents and confidence in parents' knowledge of reproductive health were also examined. A cross sectional descriptive study using structured questionnaire was conducted among 91 adolescents (11-19 years old) in North Okkalapa Township of Yangon Division, Myanmar. The majority of the people there had little knowledge on pubertal changes and STDs, and moderate knowledge on contraception. Sixty three percent of adolescents communicated at least once with their parents on reproductive health within the last 6 months: $6.8 \%$ with fathers and $62.6 \%$ with mothers. Only $15.4 \%$ talked more than three times. Girls were more likely to communicate with mothers than boys ( $79 \%$ vs. $33 \%, \mathrm{P}<0.001)$. The main topic of discussion among mother and girls is menstruation, and among mothers and boys, HIV/AIDS/STDs are mainly discussed. Regarding the ease of communication, only $15 \%$ felt comfortable talking with parents. Most of the adolescents $(89 \%)$ had positive attitude towards communicating with their parents. The findings suggest the need to involve parents in existing adolescent reproductive health programs and design interventions focusing on parents to promote parent-adolescent communication.
\end{abstract}

Keywords: Adolescent, Parent, Communication, Reproductive health, Myanmar.

\section{Introduction}

There are approximately 1.5 billion adolescents in the world, $85 \%$ of whom live in the developing world. According to United Nations Demographic Year Book, youths aged $15-24$ years constitute about $19 \%$ of the total population in Myanmar, and 10-19 years old adolescents form about $20.5 \%$ of the population. ${ }^{2}$ Adolescents are at risk of adverse reproductive health outcomes such as unplanned or unwanted pregnancy, unsafe abortion, maternal health complications, and sexually transmitted diseases (STDs) including HIV/AIDS. It is estimated that $40 \%$ of HIV infections occur among 15-24 year olds. ${ }^{3}$ These health risks may be influenced by many factors such as cultural expectations, access to information, education and health services, and gender inequities. ${ }^{4,5}$ The Reproductive Needs Assessment (1999) indicated the deficiency in reproductive health information among Myanmar adolescents. ${ }^{6}$ It is essential that teenagers be equipped with basic knowledge

\section{Practice points}

- A majority of adolescents had low knowledge on pubertal changes and STDs, and moderate knowledge on contraception.

- A majority of adolescents could identify the oral contraceptive pill, injections and condom as methods of contraception.

- A majority of adolescents had positive attitude towards communication with parents on reproductive health issues.

- A conservative attitude towards premarital sex was associated with parent-adolescent communication.

- The findings of this study suggest the need to involve parents in existing adolescent reproductive health programs.

Corresponding: Dr Yin Thet Nu Oo, Research Officer, Department of Medical Research (Lower Myanmar), No 5, Ziwaka street, Dagon township, Yangon PO11191, Yangon, Myanmar. E-mail: yinthet@gmail.com. 
on their reproductive health so that they would be enabled to make meaningful choices and decisions on matters concerning their future. Adolescents usually get reproductive and sexuality information mainly from peers and, to some extent, the media, particularly popular print and electronic media.

Adolescent reproductive health programs have expanded their focus from the individual level to the involvement of multi stakeholders including the parents, guardians, teachers and the community. ${ }^{7}$ This has created increased focus on the parents' involvement and their role in reproductive health. A strong and supportive relationship between youth and their parents is essential for their emotional and social development. Moreover, parents are role models who shape young people's perception of gender roles and influence the choices that youth make about their own sexual behaviour. ${ }^{8}$ Previous studies indicate that adolescents whose parents talk to them about issues related to sex tend to be less sexually active and more likely to use an effective means of contraception. ${ }^{8}$ Parents can be one of the main sources of information for sexual and reproductive health issues. In Myanmar's society, like many Asian countries, open discussions do not usually take place between adolescent children and parents/guardians. Sometimes parents even do not feel free to initiate conversations on sexual and reproductive health issues even if they think it is necessary to discuss it with their children. ${ }^{9,10}$

There are few studies in Myanmar on reproductive health communication between parents and adolescent children. In a study in Myanmar on the role of guardians in adolescent reproductive health behaviors, most of the guardians approved of sex education for the adolescents through media, but they did not allow their teens to discuss these matters in their presence and some $36 \%$ were willing to discuss with their children about sexual and reproductive health if they were asked. ${ }^{9}$ Another study exploring the adolescent's reproductive health needs also reported that Myanmar youth were unlikely to communicate with or receive support from parents. ${ }^{10}$

If the parents are better informed about reproductive health and equipped with skills to communicate sensitively with adolescents, it would create a positive home environment and good relationships between parents and adolescents. Evidence in some countries supports that parents should be better informed and skilled to be involved in reproductive health communication with their adolescent children. ${ }^{11,12}$ In a study of sexually active African American and Latino youth, it was found that youth whose parents held skilled, interactive and open discussions with their teens were more likely to use condoms than teens whose parents were less skilled communicators. ${ }^{13}$

To involve parents in existing youth programs or to design interventions targeting the parents of adolescents, it is necessary to find out the existing level and topics of reproductive health communication between parents and adolescents. A baseline assessment was carried out as a part of a parental intervention project to assess the level of reproductive health communication between adolescents and their parents. The specific objectives of the study were to: (i) determine the level of reproductive health knowledge among adolescents living with one or both parents, (ii) find out the existing practice of reproductive health communication between parents and adolescents, and (iii) explore the attitude of adolescents towards reproductive health communication with their parents.

\section{Materials and Methods}

This cross-sectional study is part of an intervention study targeting the parents of adolescents in North Okkalapa township of Yangon Division. A pre-tested structured questionnaire was used to collect the data from the adolescents and their parents. We recruited parents who had at least one adolescent. From each of the 12 wards (the lowest administrative tier), 8 households with adolescents were randomly selected, and one parent and one adolescent from each household were invited to participate in the study. Therefore, a baseline assessment was done among 91 adolescents excluding those who refused.

Trained interviewers used the questionnaire to collect data on background characteristics, reproductive health knowledge, reproductive health communication with parents and attitudes of adolescents towards this communication. The study was approved by the Ethical Review Committee of Department of Medical Research (Lower Myanmar), and consent was asked from the parents for their adolescent's participation. Adolescents were interviewed in a comfortable and private place. Data were checked for completeness and consistency. Data entry was done using the Epi Data 3.2 software and data analysis was performed using the SPSS version 16. Categorical variables are described in percentage and chi square test was used to explain the associations.

\section{Results}

\section{Background characteristics}

Study population consisted of 33 adolescent boys and 58 adolescent girls; age ranged from 11 to 19 years with a mean age of 15.24 yrs. All the adolescents had attended school, and a half was in the university level followed by high school level (35.2\%). Most of the adolescents (80.2\%) were currently enrolled in educational courses and $19.8 \%$ had stopped or finished their education. One fifth (20.9\%) of the adolescents were in employment and majority of them were in private organizations. Almost all adolescents were Buddhists. Table 1 outlines the details of the background characteristics of adolescents.

\section{Knowledge on reproductive health}

\section{Knowledge on pubertal changes}

Knowledge on the common age of puberty, physiological changes and psychological changes for boys and girls during puberty was explored. Nearly $40 \%$ could not correctly state the age of puberty for girls and $15.4 \%$ wrongly reported 
Table 1: Background characteristics of the study population

\begin{tabular}{|c|c|}
\hline Variable & No. (percentage) \\
\hline $\begin{array}{l}\text { Age } \\
11 \text { to } 15 \text { years } \\
16 \text { to } 19 \text { years }\end{array}$ & $\begin{array}{l}50(55 \%) \\
41(45 \%)\end{array}$ \\
\hline $\begin{array}{l}\text { Gender } \\
\text { Male } \\
\text { Female }\end{array}$ & $\begin{array}{l}33(36 \%) \\
58(64 \%)\end{array}$ \\
\hline $\begin{array}{l}\text { Education } \\
\text { Middle school } \\
\text { High school } \\
\text { University } \\
\text { Graduate }\end{array}$ & $\begin{array}{l}6(7 \%) \\
32(35 \%) \\
46(50 \%) \\
7(8 \%)\end{array}$ \\
\hline $\begin{array}{l}\text { Employment status } \\
\text { Currently working } \\
\text { Not working }\end{array}$ & $\begin{array}{l}19(21 \%) \\
72(79 \%)\end{array}$ \\
\hline $\begin{array}{l}\text { Occupation }(n=19) \\
\text { Government servant } \\
\text { Private employee } \\
\text { Own business } \\
\text { Other }\end{array}$ & $\begin{array}{l}3(16 \%) \\
11(58 \%) \\
4(21 \%) \\
1(5 \%)\end{array}$ \\
\hline $\begin{array}{l}\text { Current schooling } \\
\text { Yes } \\
\text { No }\end{array}$ & $\begin{array}{l}73(80 \%) \\
18(20 \%)\end{array}$ \\
\hline $\begin{array}{l}\text { Parents' age } \\
(45.54 \pm 5.80) \\
<\text { or equal } 45 \mathrm{yr} \\
46 \mathrm{yr} \text { and above }\end{array}$ & $\begin{array}{l}39(43 \%) \\
52(57 \%)\end{array}$ \\
\hline
\end{tabular}

the age of puberty for boys. About half $(46.2 \%)$ of adolescents were aware that there was chance of getting pregnant if one had sex in the mid-cycle. Seventy nine percent of the adolescents had misconception that masturbation can be harmful for health.

High level of knowledge of pubertal changes is defined here as correct answers to more than two thirds of 43 questions and low knowledge as knowing less than one third of correct answers.

Seventy six percent of adolescents had low knowledge on pubertal changes and $23.1 \%$ had moderate knowledge. None of the adolescents had high knowledge on puberty. Level of knowledge on puberty had no association with parent-adolescent communication. Difference in puberty knowledge level between adolescent boys and girls $(30 \%$ vs. $70 \%)$ is significant $(p=0.023)$.

\section{Knowledge on contraception}

More than $80 \%$ of the adolescents could identify oral contraceptive $(\mathrm{OC})$ pills $(87.9 \%)$, injections $(85.7 \%)$ and condom $(82.6 \%)$ as methods of contraception. When asked about other methods of contraception, $14.3 \%$ mentioned IUCD, $8.8 \%$ talked about female sterilization, $5.5 \%$ about male sterilization and only one respondent mentioned of implant. Sixty two (68.1\%) of the adolescents could identify three common methods of contraception: OC pills, injections and condom. There is a significant relation between communication with parents and knowledge on these three common methods of contraception.

A total of 11 questions on methods of contraception were categorized: 0 to 2 low, 3-5 moderate, 6 and above high knowledge. Majority $(66 \%)$ had moderate knowledge and a few had high knowledge.

Table 2: Knowledge on HIV/AIDS and contraceptive methods among the adolescents

\begin{tabular}{|c|c|c|c|}
\hline Knowledge & $\begin{array}{l}\text { Yes } \\
\text { n (\%) }\end{array}$ & $\begin{array}{c}\text { No } \\
\text { n (\%) }\end{array}$ & $\begin{array}{c}\text { Don't know } \\
\text { n (\%) }\end{array}$ \\
\hline HIV/AIDS can be cured & $9(9.9 \%)$ & $79(86.8 \%)$ & $3(3.3 \%)$ \\
\hline HIV infected person always looks thin \& unhealthy & $51(56 \%)$ & $38(41.8 \%)$ & $2(2.2 \%)$ \\
\hline HIV status can be known by blood testing & $89(97.8 \%)$ & $2(2.2 \%)$ & \\
\hline Methods of contraception & Spontaneously & Prompted & Don't know \\
\hline OC pills & $66(72.5 \%)$ & $14(15.4 \%)$ & $11(12.5 \%)$ \\
\hline Injections & $55(60.4 \%)$ & $23(25.3 \%)$ & $13(14.3 \%)$ \\
\hline Condom & $41(45.1 \%)$ & $34(37.4 \%)$ & $16(17.4 \%)$ \\
\hline Emergency pill & $2(2.2 \%)$ & $5(5.5 \%)$ & $84(92.3 \%)$ \\
\hline Withdrawal method & $4(4.4 \%)$ & $1617.6 \%)$ & $71(78 \%)$ \\
\hline Calendar method & $5(5.5 \%)$ & $19(20.9 \%)$ & $67(73.6 \%)$ \\
\hline
\end{tabular}


About half of the respondents $(46.2 \%)$ felt that condoms were the most suitable method of contraception for youth, followed by OC pills $(20.9 \%)$. However, $22 \%$ respondents did not give their opinion on the best method for young people.

\section{Knowledge on STD including HIV/AIDS}

All the respondents had heard of HIV/AIDS whereas $67 \%$ had heard of STDs. And almost all $(97.8 \%)$ of them were aware that HIV status can be found out by testing the blood. Among 61 adolescents who had heard of STDs, only $44.3 \%$ could mention at least one common symptom of STDs in males, and only $24.6 \%$ could identify at least one common female STD symptom. Table 2 shows the knowledge on HIV/AIDS and contraceptive methods among the adolescents.

\section{Knowledge on condom and attitude towards condom use}

Almost all of the adolescents had heard of condoms, and $80.2 \%$ had seen one. Older adolescents (16 to 19 yrs) were more likely to see a condom than younger adolescents ( 11 to $15 \mathrm{yrs})$. Most of the adolescents knew that condom can prevent HIV (89\%) and STDs (74.7\%). A majority (93.3\%) believed that condoms should be used in premarital sexual relationship between lovers.

\section{Reproductive health communication between parents and adolescents}

Communication practice on reproductive health within the last 6 months was explored. Among the study population who had fathers $(96.7 \%), 93 \%$ had never communicated about reproductive health matters with their fathers; only $6.8 \%$ adolescents talked with their fathers and 4 of them discussed on 2 to 3 occasions. Twelve percent of the adolescent boys and $3.6 \%$ of adolescent girls discussed with fathers. Whereas, with mothers, $62.6 \%$ adolescents had reproductive health discussions and $51.7 \%$ discussed the issues on 2 to 5 occasions. Among the adolescent boys, $33.3 \%$ talked with their mothers and among the adolescent girls, $79.3 \%$ discussed with their mothers. This difference in communication between boys and girls with their mothers is found to be significant $(p<0.001)$.

Table 3: Communication practice on reproductive health between parents and adolescents

\begin{tabular}{|l|c|c|c|}
\hline Topics & $\begin{array}{c}\text { Adolescen } \\
\text { boys (n=33) }\end{array}$ & $\begin{array}{c}\text { Adolescent } \\
\text { girls (n=58) }\end{array}$ & $\begin{array}{c}\text { Adolescents } \\
\text { (n=91) }\end{array}$ \\
\hline $\begin{array}{l}\text { Reproductive } \\
\text { health talk with } \\
\text { mother (n=91) }\end{array}$ & $11(33.3 \%)$ & $46(79.3 \%)$ & $57(62.6 \%)$ \\
\hline $\begin{array}{l}\text { Reproductive } \\
\text { health talk with } \\
\text { father (n=88) }\end{array}$ & $4(12.5 \%)$ & $2(3.6 \%)$ & $6(6.8 \%)$ \\
\hline $\begin{array}{l}\text { Reproductive } \\
\text { health talk with } \\
\text { parents (n=91) }\end{array}$ & $12(36.4)$ & $46(79.3 \%)$ & $58(63.7 \%)$ \\
\hline
\end{tabular}

Very few adolescents $(5.5 \%)$ talked with both parents on the reproductive health issues. Table 3 outlines the communication practices on reproductive health between parents and adolescents.

HIV/AIDS was the issue mostly discussed between fathers and adolescents. All four adolescent boys who communicated with their fathers reported that they discussed HIV/AIDS and other STDs. None of the boys discussed issues like condoms and sexuality with fathers. Table 4 shows the most frequently discussed reproductive health topics with mothers. Mothers and daughters discussed menstruation $(69.6 \%)$ mostly, followed by HIV/AIDS/STDs, abortion and condom use. However, only 2 sons $(18.2 \%)$ talked about menstruation with mothers. This difference in communication about menstruation between boys and girls with mothers is statistically significant $(18.2 \%$ vs. $69.6 \%, p=0.004)$. Between mother and son communication was mostly about HIV/AIDS/STDs. Least discussed issues between mothers and adolescents were contraceptives, conception and pubertal changes.

Table 4: Frequently discussed reproductive health topics with mothers

\begin{tabular}{|l|c|c|}
\hline Reproductive health topics & Boys (n=11) & $\begin{array}{c}\text { Girls } \\
(\mathbf{n}=\mathbf{4 6})\end{array}$ \\
\hline $\begin{array}{l}\text { Functions of reproductive } \\
\text { organs }\end{array}$ & $3(27.3 \%)$ & $3(6.5 \%)$ \\
\hline $\begin{array}{l}\text { Physical and emotional } \\
\text { changes during puberty }\end{array}$ & $2(18.2 \%)$ & $2(4.3 \%)$ \\
\hline Menstruation & $2(18.2 \%)$ & $32(69.6 \%)$ \\
\hline Conception & $1(9.1 \%)$ & $2(4.3 \%)$ \\
\hline $\begin{array}{l}\text { Abortion } \\
\text { Contraceptives }\end{array}$ & $0(0 \%)$ & $6(13 \%)$ \\
\hline HIV/AIDS/other STDs & $8(72.7 \%)$ & $21(45.7 \%)$ \\
\hline Condom use & $3(27.3 \%)$ & $6(13 \%)$ \\
\hline Sexuality & $3(27.3 \%)$ & $5(10.9 \%)$ \\
\hline Romantic relationship & $2(18.2 \%)$ & $3(6.5 \%)$ \\
\hline
\end{tabular}

Table 5 outlines the adolescents' attitude towards reproductive health communication with parents. Among the 58 adolescents who communicated with parents in last 6 months, almost all of them believed that the conversations were helpful. However, only $15.5 \%$ felt that the discussions with parents were comfortable. Most of the adolescents $(89 \%)$ mentioned that they should discuss reproductive health issues with parents while $6.5 \%$ have negative attitude towards communication. Seventy adolescents (76.9\%) said that they would ask the parents if they wanted to know something about reproductive health issues while 21 $(23.1 \%)$ have no intention of asking the parents or were not sure if they ever would. 
Table 5: Adolescents' attitude towards reproductive health communication with their parents

\begin{tabular}{|l|c|c|c|}
\hline Items (n=58) & Disagree/strongly disagree & Neutral & Agree/ strongly agree \\
\hline $\begin{array}{l}\text { I have difficulty in discussing reproductive } \\
\text { health issues with parents }\end{array}$ & $30(51.7 \%)$ & $24(41.4 \%)$ & $4(6.9 \%)$ \\
\hline $\begin{array}{l}\text { I feel discomfort in talking about } \\
\text { reproductive health with parents }\end{array}$ & $9(15.5 \%)$ & $40(69.0 \%)$ & $9(15.5 \%)$ \\
\hline $\begin{array}{l}\text { Reproductive health discussions with } \\
\text { parents is helpful }\end{array}$ & $1(1.7 \%)$ & 0 & $57(98.3 \%)$ \\
\hline
\end{tabular}

Most of the adolescents (90.1\%) think that their parents are able to discuss reproductive health with them although the degrees of confidence vary. Among those who confide in parents, about half felt that parents can discuss only some issues and the rest thought that their parents can discuss most reproductive health issues. This confidence in parents is related to communication: those who felt their parents can discuss the issues tend to communicate with parents than those who don't ( $70.7 \%$ vs. $0.1 \%, p<0.001)$.

\section{Gender Norms and sexual attitude}

Adolescents were asked about their attitude towards sexual relationships and gender norms. About half of the adolescents (57.1\%) accepted that lovers can be physically intimate (kissing, hugging, and caressing). However, majority of them $(81.3 \%)$ disapproved of the premarital sex between lovers. This conservative attitude towards premarital sex is different between boys and girls: girls had more conservative attitude than boys $(73.1 \%$ vs. $26.9 \%)$ $(p<0.001)$. Adolescents who communicated with their parents were more likely to have conservative attitude than those who did not communicate with parents $(94.8 \%$ vs. $69.7 \%)(p<0.05)$. Although majority of them had negative attitude towards premarital sex, $45.1 \%$ believed it is no longer a problem if contraception is used in premarital sex.

Regarding the use of condom during sex, about half of the respondents thought that adolescents will use the method during sex. Sixty two percent of them mentioned that their boy peers knew how to use a condom while $44 \%$ stated that their girl peers knew how to use the condom.

\section{Discussion}

Parents are important role models in adolescents' lives; they can directly or indirectly transmit values, traditions and lifestyles to their children. They also play an integral part in the overall development of adolescents, especially mental and social development. Since reproductive health issues are critical for the wellbeing of adolescents' health, this study made an effort to explore the extent and content of reproductive health communication between adolescents and parents. It was found that girls tend to have more knowledge on adolescent pubertal changes than boys. Many adolescents could identify three common methods contraception (OC pills, injection, and condom). Though all the adolescents had heard of condom, only $83 \%$ mentioned it as a contraceptive method.

We found that there is a significant difference in reproductive health communication between adolescent boys and girls with their mothers; girls are more likely to talk with mothers than boys. It is possible that girls are likely to ask about menstruation to their mothers since female family members traditionally teach daughters about this monthly cycle when they reach puberty. A study in China also reported significant gender difference in the pattern of sex communication; male adolescents are more likely to talk with fathers and female adolescents with mothers. ${ }^{11}$ Parents may have preferences in splitting gender roles while holding reproductive health discussions with their adolescent children. ${ }^{14}$ In a similar parent adolescent communication study among the African-American youth, male and female adolescents are more likely to discuss sexual topics with their mothers than fathers. ${ }^{13}$ This study found that popular topics of discussion among male adolescents were STDs/HIV and condom use. Among the female adolescents, menstrual cycle was the common topic of discussion with mothers. ${ }^{13}$ Also in this study, common topic among mother and son was HIV/ATDS/STD and among mother and daughter it was menstruation.

A great majority of adolescents (89\%) have positive attitude towards reproductive health communication with parents, whereas $76.9 \%$ of the adolescents have intention of asking the parents if they have a reproductive health question in the future. The proportion of adolescents reported to have discussed reproductive health with parents is $63.7 \%$ in the study. Therefore, it is possible that there is difficulty in initiating conversations between parents and adolescents.

Adolescents might not feel free to ask or they might be afraid of the judgmental behavior of parents. It can be seen that only $17.5 \%$ (11 out of 63 ) of those who communicated with parents felt comfortable.

All the respondents had heard of HIV/AIDS whereas only $61(67 \%)$ had heard of STDs and very few could mention the common symptoms of STDs. This finding highlights that adolescents need to be given health education on STDs. 
Culture and religion are important factors influencing reproductive health. In this study, however, participants are predominantly Buddhist, and there is no obvious difference in the knowledge on reproductive health, and practice of reproductive health communication in the Buddhist and other religions. Most of the adolescents $(81.3 \%)$ have a conservative attitude towards premarital sex. Adolescents who hold discussions with parents tend to have more conservative attitude than those who do not. This highlights the role parents play in transmitting family and cultural values directly or indirectly to adolescents. A Myanmar study among guardians of adolescents in rural areas reported that parent's involvement in adolescent reproductive health was low. ${ }^{9}$ Our findings also highlight that the level and extent of reproductive health communication are limited. Since parents can play major role in contributing towards positive reproductive health outcomes of adolescents by creating a favorable environment of communication, it is necessary to sensitize parents on the way they communicate reproductive health issues with adolescent children and encourage them to seek information on adolescent reproductive health and sexuality issues. The findings of this study suggest the need to strengthen the involvement of parents in existing adolescent reproductive health programs and design interventions focusing on parents. We also suggest highlighting the importance of parenting, parent-adolescent relationships, and ways and process of communication on sexual and reproductive health through qualitative research. The findings of such research would be valuable for designing and selecting contents of future parental training programs.

Details of communication such as ways, approaches and choice of words may also influence the parent-adolescent communication. Nature of communication may be two-way between parents and adolescents or one way from parents. Ways of communication were not explored in the study; qualitative approaches are recommended to study the detailed ways and approaches of communications between parents and adolescents.

\section{Conclusions}

Majority of adolescents had low knowledge on pubertal changes and STDs and moderate knowledge on contraception. This finding highlights that adolescents need to be given health education on STDs. A majority of adolescents had a positive attitude towards communication with parents on reproductive health issues. However, most of them felt uncomfortable to talk about reproductive health with parents. It is possible that there is difficulty in initiating conversations between parents and adolescents. Adolescents might not feel free to ask or they might be afraid of the judgmental behavior of parents. Parents should be encouraged to talk and to give their adolescents chances for open discussions. This needs communications skills of parents. We would like to suggest the need to involve parents in adolescent reproductive health programs and to provide them with reproductive health training. Future qualitative studies are recommended to study the detailed ways and approaches of communications between parents and adolescents.

1. WHO. Young people and sexually transmitted diseases. Fact Sheet $\mathrm{N}^{\circ}$ 186. Geneva: World Health Organization, 1997.

2. United Nations. 1998 Demographic Year Book. New York: Economic and Social Affairs, United Nations, 2000.

3. UNAIDS. Report on the Global AIDS Epidemic 2010. Geneva: UNAIDS, 2010.

4. International Center for Research on Women (ICRW). Vulnerability and opportunity: Adolescents and HIV/AIDS in the developing world. Washington DC: ICRW, 1996.

5. PATH. Adolescent Girls and their Rights. Adolescent Girls' Health and Nutrition with special emphasis on reproductive health. Background paper for UNFPA expert group meeting for adolescent girls and their rights. Washington DC: PATH, 1997.

6. Ministry of Health and UNFPA. A reproductive needs assessment in Myanmar. Yangon: Ministry of Health and UNFPA, 1999.

7. Horizon Project. Peer education \& HIV/AIDS: Past experiences, future directions. Washington DC: Population Council, 2001.

8. Pathfinder International. In Focus: Focus on young adults. Involving parents in reproductive health education for youth. www.pathfind.org/focus.htm (Accessed 15 Oct 2011)

9. Win LL, Shwe S, Wai KM, Myint CC et al. Role of guardians in adolescents' reproductive health behaviours in rural area. Myanmar Health Sci Res J. 1998;10:64-7

10. Tin N. Exploring adolescents reproductive health needs in Myanmar. Myanmar Health Research Congress. Program and Abstracts, 2003: 36.

11. Zhang L, Li X, Shah IH, Baldwin W, Stanton B. Parentadolescent sex communication in China. Eur $J$ Contracept Reprod Health Care. 2007;12:138-47.

12. Biddlecom A, Awusabo-Asare K, Bankole A. Role of parents in adolescent sexual activity and contraceptive use in four African countries. Int Perspect Sex Reprod Health. 2009;35:72-81.

13. Whitaker DJ, Miller KS, May DC, Levin ML. Teenage partners' communication about sexual risk and condom use: the importance of parent-teenager discussions. Fam Plann Perspect 1999;31:117-21.

14. Kiragu K, Obwaka E, Odallo D, Van Hulzen C. Communicating about sex: adolescents and parents in Kenya. AIDS STD Health Promot Exch 1996;3:11-3. 